\title{
Recuperação do Centro da Cidade de São Paulo e sua Importância para o Turismo e Lazer Urbano ${ }^{1}$
}

\section{Flávia Roberta Costa $a^{2}$}

RESUMO: Diagnóstico do centro da cidade de São Paulo, com ênfase em seus principais problemas e no estágio atual de seu processo de revitalização. Apresentação de propostas de utilização do centro para turismo e lazer, com base na interpretação dos atrativos turísticohistóricos.

PALAVRAS-CHAVES: Centro de São Paulo (cidade); recuperação; revitalização, propostas de utilização; turismo e lazer urbano.

ABSTRACT: Diagnostic of the city-center of São Paulo, emphazising its main problems and the actual revitalization process. It presents utilization proposals of the city-center for tourism and leisure, based on the interpretation of its historic-touristic attractions.

KEY WORDS: São Paulo city-center; recuperation; revitalization; utilization proposals; tourism; urban leisure.

\section{Introduçāo}

Embora sejam comuns os exemplos de uso isolado de bens culturais aproveitados peloturismo no País, a afirmação de que estes elementos ainda não são utilizados de forma eficiente como recursos para a atividade turística é verdadeira, principalmente em se tratando de conjuntos arquitetônicos. O turismo cultural com

1. Este artigo é parte do trabalho de conclusão do Curso de Turismo apresentadoem 1994 (Costa, 1994), na Escola de Comunicações e Artes da Universidade de São Paulo, sob a orientação do prof. dr. Mário Pires.

$\therefore$ End. para corresp.: Rua Nicolau Alayon, $326-048-000$ - São Paulo - SP - Brasil. 
base em centros históricos revitalizados contribui não só para o incremento ou captação de recursos financeiros como estimula a preservação de edifícios, aran. tido-lhes seu uso original ou adaptado-os a novas funções pela utilizaç exemplo, da técnica do refurbishment, que recupera fachadas e moderniza interiores. O turismo é uma das formas de compatibilizar crescimento econônico e preservação dos recursos patrimoniais, sejam eles naturais ou culturais.

A mais recente restauração de conjuntos arquitetônicos com o objetivo de transformá-los em atrativos turísticos foi a recuperação do bairro do Pelourinao, na Bahia. Esta recuperação foi acompanhada de intensa campanha publicitária, cujo foco abrangia também as belezas naturais da região, que atingiu os objetivos traçados: divulgar o produto Bahia no Brasil e no Exterior, aumentando os lluxos turísticos e criar novos pólos para o desenvolvimento da atividade. De área de concentração de prostitutas e marginais, portanto sem condições de aproveitamento turístico, o bairro tornou-se um dos mais importantes atrativos de uma região até então conhecida apenas por seus recursos naturais. Hoje, o Pelourinho é um importante centro cultural, comercial e turístico e esta utilização salutar vem obtendo resultados positivos para a economia e imagem do Estado.

Em São Paulo, toda a área central da cidade tem se caracterizado pela deterioração de sua qualidade urbana, pela degradação física e pelo esvaziamento de suas funções tradicionais, operadas por um tipo de desenvolvimento econômico e urbanístico que sempre criou novos espaços mediante o sucateamento dos já existentes. Porém a grande quantidade de representativos remanescentes $\mathrm{dc}$ diferentes períodos da História paulista, somada a elementos contemporâneos e reunidos em um espaço físico relativamente pequeno, deve ser encarada como um relevante fator de incremento e atração de fluxo turístico para a atividade na Capital.

A possível utilização dos bens históricos como atrativos complementares à atividade turística paulistana é o enfoque principal deste artigo. Apresenta-sc, em primeiro lugar, um diagnóstico do centro da cidade de São Paulo, destacando seus principais problemas e o estágio atual de seu processo de revitalização. Em segundo lugar, apresentam-se propostas de utilização desse centro para turismo e lazer urbano. Por fim, nas considerações finais, ressalta-se que a revitalização do centro da cidade de São Paulo não pode se transformar em um atrativo "imaginário", mas sim deve se basear na interpretação, uma das mais modernas técnicas de aproveitamento de atrativos turísticos, neste caso históricos.

\section{Problemas e Estágio Atual do Processo de Revitalizaçāo}

Se no Pelourinho o desgaste foi causado pelo abandono dos casarões pelos proprietários, conseqüência de seu empobrecimento, deixando o bairro paráa que fosse tomado por marginais e moradores de baixa renda e transformando-o num verdadeiro conjunto de cortiços, a deterioração foi determinada por motivos inversos. O enriquecimento da cidade e a conseqüente necessidade de moderniza- cão requerida pelos proprietários dos imóveis, acabaram por levar à formação de bairros mais nobres.

Mais recentemente, a crescente valorização do uso de transporte particular a privados, a implantação indiscriminada a carência de estacioname segurança deram início a um processo ainda mais efetivo de calçadões e a falta de imagem do Centro. O que veio se somar à polinucleação de desgaste progressivo da imagem processo de desenvolvimento econômico e urbano ea outros fenômenos paralelos ao proces fenômenos, dois destacam-se como mais de São Paulo. importantes

- a proliferação de shoppings centers

- o deslocamento da verticalização imobiliária.

O número de shoppings centers da cidade cresce a cada dia. Em sua estrutura oferecem os mesmos atrativos que o Centro, além do conforto funcional (acessibilidade, estacionamento, segurança, proteção contra intempéries etc.). Nos últimos anos, acrescentaram às suas funções comerciais diversificadas a vantagem últimos anos, acrescentaram às suas funçôes comerciais de alimentação, cinemas e centros de diversão) e outros tipos de serviços (como agências bancárias, correntes, aluguel de automóveis, compra e venda de telefones, câmbio etc.).

A migração dos arranha-céus, por sua vez, ć resultado da crescente especulação imobiliária. Esta transferência acarretou uma baixa renovação dos estoques de edificações, levando o Centro a um processo contínuo de desvalorização pecuniária. Mantendo seus prédios com as características interiores originais, as edificações do Centro começaram a apresentar desvantagens quando comparadas com edifícios localizados em novos pólos, que primam por suas técnicas construtivas de ponta, espaços organizados conforme necessidades atuais da demanda, modernos equipamentos de segurança, disponibilidade de estacionamento para veículos particulares e fácil acesso para o transporte individual

Assim, o problema do Centro concentra-se no processo de desqualificação funcional, que o torna cada vez mais incapacitado para a competição com outros centros secundários da metrópole. Impedir o declínio desta área e requalificar os espaços públicos têm sido o objetivo da iniciativa pública - representada por diferentes secretarias municipais, reunidas no ProCentro - e privada, representada pela Associação Viva o Centro ${ }^{3}$.

\footnotetext{
3. A Associação Viva o Centro - Sociedade Pró Revalorização do Centro de São Paulo, é uma entidade sem ins lucrativos, fundada em ll de do Comércio de São Paulo, Instituto dos Aruites de São Paulo, Teatro Municinal - ,entre outros, visando buscar alternativas recurso dos Arquitotos do Sa Talo, Tealo Mo Pro os mesmos objetivos da Asrocin ñ
} 


\section{Problemática Atual do Centro da Cidade}

Segundo a Associação Viva o Centro e o ProCentro, a região central da cidade aponta quatro problemas principais, que vêm contribuindo para a sua desvalorização e esvaziamento:

- deterioração ambiental e paisagística;

- dificuldade de acesso, circulação e estacionamento

- insuficiência e crescente obsolescência do estoque imobiliário;

- deficiência da segurança patrimonial c pessoal.

Para a resolução destes problemas detectados facilmente através a té đe uma simples caminhada pelo Centro, as duas entidades traçaram diretrizes que, no sel entender, devem sanar os quatro obstáculos citados para a requalificação đả região São, porém, diretrizes que receberam semprc um tratamento superficial, não fornecendo informações suficientemente concretas sobre as ações a q̧ue darão origem.

\section{Deterioraçāo Ambiental e Paisagística}

É o elemento constante em todo o Centro, não se caracterizando especificamente de acordo com o logradouro em que se localiza. Como diretrizes básicas para a resolução destes problemas, o ProCentro destaca:

- implantação de coordenação unificada para qualquer projeto na árca, evitando ações isoladas;

- priorizar a qualidade ambiental e paisagística em qualquer intervenção realizada;

- padronizar equipamentos e mobiliário urbano, resguardando as especifidades dos locais onde estão instalados;

- tornar mais claras as regras de ocupação e utilização dos espaços, públicos ou não;

- fiscalizar o cumprimento de leis relativas ao uso do espaço público;

- estabelecer como pólo-piloto para intervenções a praça do Patriarca.

- compensar adequadamente proprietários de bens tombados, incentivando sua conservação;

- incentivar a conservação e recuperação de fachadas e melhoria da segurança das edificações;
ProCentro;

- incentivar a exocução de painéis artísticos em empenas cegas (com exceção dos edificios preservados), criando uma nova ambientação urbana;

construir "pop shoppings", ancorados na mesma concepção dos shoppings centers tradicionais, com uma estrutura simplificada e mais barata, que transforcamelôs em comerciantes regularmente estabelecidos;

estabelecer pólos de recuperação urbana que possibilitem a concentração de acões, para que as transformações tornem-se mais evidentes e difundam-se para outras áreas.

Como iniciativas já concretizadas para a melhoria dos aspectos ambientais Como inisticos da região, aparecem como intervenções mais relevantes a conclusão da reurbanização do Vale do Anhangabaú, a restauração do Teatro Municipal, reabertura do Cine Cairo, a restauração do edificio da Bolsa de Mercadorias \& Futuros, a restauração da Agência Central dos Correiros, a restauração do antigo Solar da Marquesa de Santos (atualmente abrigando o Museu da Cidade), a restauração do Palácio das Indústrias (atual sede da Prefeitura Municipal) e início das obras de recuperação do Parque D. Pedro II, a recuperação da Biblioteca Municipal Mário de Andrade, a recuperação do Largo do Paissandu e a restauração da Estação JúlioPrestes. Outras obras foram iniciadas, como o restauro da fachada do antigo Banco SãoPaulo (atual Secretaria deEsportes e Turismo do Estado de São Paulo), a restauração da fachada do Mosteiro de São Bento e alguns itens do seu interior, a restauração do Viaduto do Chá e a reforma da cobertura do Mercado Central.

\section{Dificuldade de Acesso, Circulação e Estacionamento}

Segundo o ProCentro, a área central apresenta características de seu sítio original que acarretam problemas ligados à circulação, ao acesso e estacionamento. Atualmente, o Centro é alvo de diferentes projetos que visam melhorar a acessibidade dos automóveis, a fluidez do transporte coletivo, as condições de operações de carga e descarga e o conforto e segurança dos pedestres em circulação. Estas inicitivas estão sendo desenvolvidas pela Secretaria Municipal de Transportes-SMT -, Companhia de Engenharia de Tráfego - CET - e Departamento de Serviço Viário - DSV.

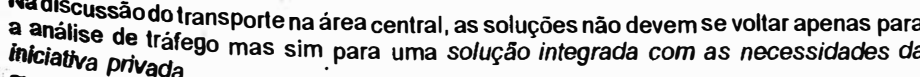

a análise deâo do transporte na área central, as soluçōes não devem se voltar apenas pa iniciatva privada 
Para o desenvolvimento desta solução integrada, foram traçadas diretrizes básicas para a melhoria da acessibilidade na região central, sintetizadas nos seguintes itens:

- melhorar a qualidade da circulação de pedestres, objetivando:

- reduzir a ocorrência de atropelamentos;

- melhorar as condições da área de circulação de pedestres;

- implantar um sistema de orientação para pedestres;

- melhorar a qualidade do transporte coletivo

- reduzir as distâncias percorridas a pé;

- otimizar o uso das áreas de terminais

- reduzir pontos finais em áreas inadequadas;

- racionalizar o sistema de transporte coletivo;

- melhorar o sistema de transporte de cargas, visando:

- facilitar o abastecimento da área central;

- minimizar conflito transporte de carga versus ônibus, carros e pedestres

- reduzir a poluição ambiental;

- facilitar a acessibilidade de veículos particulares, através de:

- adequação física do sistema viário;

- incentivo ao uso da infra-estrutura nos períodos de baixa ocupação (entre-pico, noturno, feriados, sábados e domingos);

- controle mais eficiente sobre a circulação de veículos em áreas restritas;

- adoção de medidas reguladoras para a circulação de veículos em áreas de tráfego seletivo.

Algumas medidas para a melhoria da acessibilidade da região já foram implantadas, como a proibição da circulação de caminhões na rótula ${ }^{4}$ das 6 às $9 \mathrm{~h}$ e das 16 às $21 \mathrm{~h}$. A Prefeitura também estuda a ampliação da zona marrom (área para estacionamento de caminhões).

\section{Insuficiência e Crescente Obsolescência do Estoque Imobiliário}

Para a Associação Viva o Centro, esteé um dos maiores problemas da região $\mathrm{e}$, somado à falta de segurança patrimonial e individual, é uma das causas principais de sua desqualificação funcional.

4. A chamada "rótula" é um corredor formado pelo Parque D. Pedro II, Av. Senador Queiróz, Av. Ipiranga, Av. São Luis,
Praça da República, R. Maria Paula, Praça João Mendes, Viaduto Dona Paulina, R. Anita Garibaldi, Av. Rangel Pestana, R. da Figueira e Av. Mercúrio.
Uma das primeiras medidas a serem tomadas é a ampliação da área da Uma das primeiras medidas a ser motivos diversos, não especificados pelo Operação Urbana Anhangabaú (que por mara os limites do Centro, passando a se ProCentro, não surtiu o efeito desejado) para os baseia-se na permissão de venda denominar Operação Urbana Centro. O projeto baseia-se na permistecidos na Lei de área adicional, objetivando aumentar os limites construtivos estabelecidos naLei de Zoneamento, com prévia aprovação da Préitura. Com a extensão deste lar a realização de investimentos conquistar melhorias para a paisagem da estímulo região. problemas do estoque imobiliário:

- criar incentivos legais (como isenção do IPTU ou ISS por prazos estabelecidos) para atração de atividades de aumentando a diversificação de usos da região;

hotelaria para o Centro, aumentando a diversificação de usos da região;

- rever a legislação de estacionamentos e garagens, possibilitando o aumento do número de vagas fora das vias públicas;

- estimular a criação de estacionamentos subterrâneos nos seguintes locais: largo do Paissandu, rua da Consolação, proximidades da rua 25 de Março, largo São Francisco e praça da República;

- intensificar a fiscalização dos imóveis irregulares;

- incrementar o uso institucional da área central, com a instalação de secretarias e outros órgãos da administração municipal, estadual e federal;

- compensar adequadamente proprietários de imóveis tombados, apoiando sua manutenção através de incentivos "claros e convidativos";

- modernizar o estoque imobiliário, adequando-o às condições de conforto térmico, circulação interna e segurança (principalmente contra incêndios), considerando a técnica do refurbishment.

Por ser considerado um desestimulante para a conservação de edifícios de valor histórico-arquitetônico, o tombamento vem sendo complementado (e muitas vezes substituído) por instrumentos que procuram despertar o interesse do proprietário na manutenção de imóveis de importância histórica significativa. A técnica do refurbishment, por exemplo, já vem sendo adotada com sucesso na recuperação de vários imóveis do Centro, como no antigo Grande Hotel, construção de 1909 localizada no largo do Café. Sua fachada foi quase totalmente recuperada, com instalação de uma réplica perfeita de sua cúpula original. No interior do imóvel serão insatalados bares e restaurantes, "construindo" um mini-shopping 
gastronômico (seguindo o bem sucedido Dauntaun Fast Food, na nua XV de Novembro, 265)

Um importante exemplo de recuperação daqualidade patrimonial incidindo na recuperação dos valores imobiliários é o edifício Jayme Loureiro. Localizado na rua Sete de Abril, o projeto de Ramos de Azevedo, de 1927, passou pela mesma trajetória de outras edificações históricas do Centro. Em 1982, 24 de seus 6 conjuntos estavam desocupados. Segundo o proprietário Celso Figueiredo Filho esse quadro se

manteve até 89. Percebi que teria que transformar meu prédio de "velho" para "antigo" Recuperamos as fachadas, pintamos e adequamos as instalaçōes elétricas e hidráulicas à legislaçāo. Menos de um ano depois, todas as salas estavam ocupadas - e por um prę̧o $30 \%$ superior àmédia da regiāo. Oinvestimento foi recuperado em seis meses e o edificio ganhou um charme irresistivel. (Associaçāo...,1993:4)

No caso de fachadas restauradas, a redução média da taxa de IPTU cobrad será de $40 \%$, podendo chegar a $60 \%$, dependendo do envolvimento no projeto de restauro, durante 2 anos. A implantação destes descontos depende da aprovaçãoda Câmara Municipal.

É importante salientar que a recuperação de edificações através do refurbishment ou o simples restauro de fachadas são as mais correntes ações que vêm sendo adotadas, principalmente por se reverterem, em prazos relativamente pequenos, em benefícios diretos a seus proprietários (como no citado caso do edifício Jayme Loureiro) e também por oferecerem uma "maquiagem" à região central, dando-lhe um aspecto de mais revitalizada do que realmente cstá.

\section{Deficiência da Segurança Patrimonial e Pessoal}

A questão da segurança patrimonial e individual é uma das mais importantes abordagens para a recuperação do Centro Velho, por representar, segundo parecer técnico do ProCentro, um dos problemas mais graves da região.

Desde junho de 1993, a Polícia Militar vem instalando câmeras de vídeo adaptadas às cabines policiais, com o objetivo principal de prevenir assaltos a pedestres. A Secretaria de Segurança Pública do Estado pretende, ainda, de acordo com o Macro Plano de Segurança da Capital, modernizar a estrutura do policiamento, principalmente com recursos materiais e humanos. Estas intervenções melhorarão a qualidade da segurança pessoal durante o dia. O mesmo não se verifica para o período noturno, ou para a melhoria da qualidade da segurança das edificações, onde só estão previstas algumas diretrizes básicas, sem ao menos prazo determinado para início de sua implantação.

Como diretrizes básicas elaboradas pelo ProCentro, destacam-se: melhorar as condições estruturais que influem nas questões de segurança, como limpeza e iluminação;

apoiar programa de requalificação das edificações, melhorando suas condições de segurança;

retirar fachadas falsas ou grandes anúncios que dificultem o acesso de bombeiros em caso de incêndio

- apoiar entidades que trabalhem com menores carentes;

- restringir a concentração de ambulantes, principalmente no Centro Velho.

\section{Projetos de Intervenção na Região Central}

Para facilitar os trabalhos, incentivando a concentração de ações c invesimentos, foram estabelecidos quatro projetos de intervenção, com o objetivo de tornar as transformações mais evidentes. Estes projetos contêm, além de elementos especificos, as resoluções acima cxpostas para os quatro problemas tratados.

O Projeto Patriarca, o mais importante dos quatro estabelecidos, abrange aárea formada pela praça do Patriarca c Galeria Prestes Maia. Pretende-se restaura as fachadas de todo o setor leste da praça e da igreja (nestc caso, a restauração abrangerá também o interior da edificação), estendendo-se às ruas Líbero Badaró eSão Bento. Os terminais de ônibus ali localizados serão retirados e a cobertura da Galeria substituída por um pórtico/cobertura, emblema do projeto. $\mathrm{O}$ piso em mosaico português será recomposto, os postes decorativos de iluminação remodelados e a praça e edifícios restaurados reccberão uma iluminação especial. Os ambulantes serão retirados. Como se vê, as diretrizes traçadas para toda a região c expostas acima estão presentes neste projeto específico.

A Galeria Prestes Maia recebcrá um tratamento especial, ainda indefinido entre uma reorientação de usos, passando a abrigar atividades de suporte ao usuário do Centro, cono agência dos Correios, posto telefônico, farmácia, banca de jornais, livrarias, café e bar, c a instalação de um centro cultural filiado ao Museu de Arte de São Paulo - MASP.

O projeto Fachadas do Centro visa fornecer um conjunto de

(...) especificaçōes técnicas, condiçōes juridicas e administrativas, incentivos fiscais e um suporte de marketing e comunicação para viabilizar o patrocinio da iniciativa privada ao restauro de fachadas do Centro. (ProCentro: 1994, 10)

Um dos objetivos a ser alcançado é criar pólos de atração turística através da aparente recuperação da edificações. Scrão criados vários incentivos, como 
isenção do IPTU para edificios com interesse de preservação e autorização exploração de publicidade nos tapumes de obras em restauro e em empenas cegas (através de painéis artísticos). Como já foi destacado, a recuperação de fachadas uma das poucas intervenções que já está em andamento entre as muitas diretrizes programadas.

O ProCentro desenvolveu também o Plano de Incentivo à Cultura, Lazer Turismo na Região Central. Suas ações foram divididas entre o poder público e iniciativa privada.

A inauguração do Museu da Cidade, localizado no antigo Solar da Marques de Santos, é um exemplo de ação já desenvolvida na área cultural. Segundo Departamento de Patrimônio Histórico da Secretaria Municipal de Cultura, museu funcionará prioritariamente para a realização de eventos do que para mostras permanentes. Para as exposições, contará com o acervo da Arquivo Histórico Municipal.

O quarto programa, chamado Centro Acessivel, em nada contribui con inovações para a melhoria da acessibilidade da região. Seu conteúdo é um resumo das diretrizes já expostas como solucionadoras do problema acesso.

\section{Propostas de Utilizaçāo do Centro para Turismo e Laze Urbano}

No Brasil, o turismo com base em atrativos culturais e, especificamente, no patrimônio histórico, agrada os turistas internos mais pela diferente atmosfera que oferece, proporcionando a tão desejada "fuga do cotidiano", que por seu valor histórico intrínseco. Este fator não é característico apenas dos atrativos paulistanos, podendo ser identificado também em outros centros brasileiros de atratividade cultural solidificada, como Ouro Preto (MG), Parati (RJ), São Luís (MA) e o ja citado Pelourinho (Salvador, BA)

Os fluxos internacionais, principalmente europeus e norte-americanos, possuem maior tradição na utilização de sítios históricos como atrativos turísticos (caso de Barcelona, Paris, Roma, Loire, Veneza, Atenas, Lisboa, Praga, Viena, Lima, Santiago, Charleston e tantas outros). Os atrativos históricos brasileiros representam apenas um fator complementar a atrativos mais potencializadores de fluxos estrangeiros, como os naturais - principalmente praias. Há que se lembrar, também, que o trabalho promocional realizado para a divulgação do País está calcado principalmente em suas belezas naturais

A utilização de elementos culturais como atrativos turísticos fol detalhadamente tratada em pesquisa realizada no Canadá (Ritchie \& Zins : 1978). Nesta pesquisa, percebeu-se que os mais importantes fatores de atratividade turística são os recursos naturais, seguidos pelas características culturais do local. Detectou-se que, quando da análise dos elementos culturais, turistas e residentes preferem as formas de atrativos ditas "animadas", categoria que incluiu sítios históricos revitalizados e interpretados, festivais com base em tradições antigas e mientação de base histórica. As formas "inanimadas", ponsideradas tão como edifícios, pinturas, esculturas e residentes.

motivadoras na opinião de turistas culturais existentes

Tal conclusão, mesicaria o porquê dos atrativos históricos, principalmente entre Brasil e Canadă, exp não influenciarem visitação por sua significação, mas arquitetônicos, geralmente na sim pelo "clima" que profetivo de interpretação histórica destes bens, que lhes Pelourinho, um trabalho efetivo de int solicitadas por residentes e visitantes.

ofereça as características "animadas" solicitadas por residentes e visitantes. Apenas revitalizar o Con atrairá visitantes ao local. É importante que seja dos acessos e da segurança realizado um trabalho de interpretação historica ', que forneça elementos sufucientes para o entendimento daquele sítio, de suas edificações e monumentos, da sua Historiaño de base histórica, a constância de eventos culturais e artísticos, ambientaça de bas visitantes, palestras, passeios aũo-gum computadorizadas, multimídias e a maciça divulgação centrais de in elementos primordiais para a conservação deste e de qualquer constituem-se em elementos primordiais para assegurará que a conservação dos edifícios seja complementada por sua utilização, através das visitas realizadas, e vice-versa representando um elo de ligação entre o usuário e o atrativo.

Apesar de primar pelo entretenimento e diversão, a interpretação otimiza a atividade turística, na medida em que propicia um conhecimento mais profundo do local. Ela desenvolve, ainda, atitudes positivas de proteção/conservação do patrimônio, seguindo a teoria do "conhecer para preservar". Outros elementos como educação formal e informal e o desenvolvimento de uma identidade para os residentes são considerados, assim como a procura por trabalhos com todas as idades e grupos sociais.

Por outro lado, muitos dos paulistanos permanecem na capital nos fins-desemana e mesmo numa cidade com os atrativos de São Paulo, um incremento na oferta de lazer para uma demanda imensamente grande deve ser procurado. A quantidade de superfícies livres dos espaços públicos urbanos, como o Parque Anhangabaú por exemplo, é extremamente escassa e, além da insuficiência, caracteriza-se por ser pouco utilizada pela grande parte dos paulistanos, como acontece em geral com todo o Centro.

Mais que considerar a região um novo clemento a ser trabalhado como atrativo capaz de motivar novos fluxos turísticos, incrementando em números e cifras os já existentes, o Centro deve ser entendido como um atrativo complementar últimotivação de negócios e eventos, esta sim solidificada $\mathrm{c}$ em expansão pelos últimos investimentos realizados, através da política adotada pelo trade para o turismo na Capital $\mathrm{O}$ incentivos, através da política adotada pelo trade para o

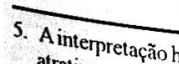

atrativo, chă histórica visa traduzir na forma de in Co sitios históricos (revitalizados ou não) edificações, monumentos etc. 
alternativas de lazer para a população paulistana, baseadas na interpretação histórica, deve ser também fator preponderantemente considerado, em paralelo ao incentivo a programas de receptivo na região central.

Todas as diretrizes citadas no decorrer deste estudo como ações a serem realizadas para a revitalização do Centro influenciam diretamente o futuro dese volvimento de atividades turísticas e de lazer, mesmo que representem diminuts melhorias para a infra-estrutura da área. Algumas outras diretrizes diretament referentes à cultura, ao lazer e ao turismo também foram traçadas e estão contida no Plano de Incentivo à Cultura, Lazer e Turismo na Região Central, do ProCentro caracterizando-se, pelo mesmo tratamento superficial e pouco informativo das restantes.

Algumas outras ações podem ser implantadas como complementares às jà discutidas e apresentadas, visando melhorar as condições do Centro e operacionaliza o turismo e o lazer da região. Segundo a Associação Viva o Centro, a implantação completa das ações de recuperação só será possível num longo prazo, delimitado entre 5 a 10 anos. O fomento das atividades de turismo e lazer, entretanto, pode ser iniciado a partir de agora, inclusive como forma de divulgação das ações realizadas e da própria importância histórica da região.

É necessário que, para a introdução de qualquer programa, se atente sempre para a temática do Centro, baseada em sua evolução como uma síntese da história paulistana, adotando-a efetivamente como linha-mestra a ser seguida. Para tanto, a "atmosfera" do Centro deve ser sim diferenciada do restante da cidade propiciando a identificação do local como único, especialmente planejado combase nas mais atuais práticas urbanísticas e na preservação de seus elementos diferenciadores, de valor histórico-cultural.

Para a melhor fruição dos espaços urbanos pela população paulistana, a arborização de praças e outra áreas livres deve ser observada. Deve-se atentar, entretanto, para as dificuldades de plantio e crescimento oferecidas pelos equipamentos localizados no subsolo da região (como o metrô, por exemplo). Para solucionar este problema, as espécies devem ser cuidadosamente escolhidas, assim como o local de seu plantio. Equipes especializadas devem ser destinadas à freqüente manutenção e o plantio aleatório deve ser combatido. Os projetos paisagísticos originais devem ser revistos, alterados se necessário, e implantados de forma integral.

É fundamental também a implantação de um centro de apoio ao visitante, que, mais que uma central de informações, seja responsável pelo bem estar do visitante da região. Esta central deve possuir santitários e bebedouros públicos extremamente limpos, visando completar a infra-estrutura pública da área e apoiar o que já vem sendo oferecido por estabelecimentos particulares. Deve possuir também um posto de informações turísticas e culturais, com atendimento bilingue e complementação de folhetos informativos ou de divulgação, mapas, guias listagem de meios de hospedagem e alimentação, eventos culturais, artísticos e esportivos, teatro, cinema etc., localizados na região central As informações deven ser informatizadas e, dependendo dos recursos disponiveis para o projeto, a ão de uma central de informações computadorizada para utilização direta mplantaçãode uma cen estudada. Este centro de apoio ao visitante seria também do visitante poderia ser estue listagem de itinerários de responsável por serviços de gu de táxi. Uma central de venda de souvenirs (com respus, linhas de metro e pontos de slides, cartões postais, posters, cacializados e/ou detalhados) poderia complemenfico (como livros, guias mais esceça Como local ideal para sua instalação, sugere-se a tar os serviços de infor histórico ou o uso do espaço da Galeria Preste Maia, já que escolha de um predio histo Centro e do ProCentro pretende transformá-la em um projeto da Associação Viva o Centró do um dos pólos de proje cultural. Sua localização é ideal centro cultural. Seitos conseguidos através das ações revitalizadoras. A Anhemb irradiação dos efeitos de São Paulo, por ser o representante oficial do turismo na Turismo e Eventos de Sabilizar-se pela sua execução, aliando-se a outros órgãos cidade, deveria responsabilizar-s

públicos e à iniciativa privada. A humanização do Ceno mobiliário urbano, para a realização de calçadas, pisa melhor locomoção de deficientes fisicos.

A ambientação de base histórica é hoje considerada como um dos mais importantes elementos da interpretação de atrativos histórico-culturais evem sendo utilizada em sítios de atratividade consagrada, principalmente nos Estados Unidos.

A ambientação de base histórica distingüe-se por utilizar-se dos recursos da ambientação - cenografia, vestuário, iluminação, música, alimentação, dramatização etc. - para o (lich te com a época e/ou representatividade que distinguiram essas edificaçōes, a ponto de justificar sua preservação e conservação (Pires \& Basso:1992, p. 44)

Pela ampla gama de períodos representados pelas edificações do Centro, a ambientação em diferentes remanescentes seria bastante frutífera c indicada tanto para visitações turísticas como para atividades de lazer. Seu uso na educação formal e informal também já vem sendo bastante empregado, como apoio ao conteúdo disciplinar de História. A ambientação, porém, apoia-se $\mathrm{cm}$ ações de marketing, não devendo acontecer de forma isolada e mal planejada, mas sim como integrante de um plano geral administrativo ou mesmo de marketing.

A organização de roteiros para passeios auto-guiados é outra forma interessante de interpretação que tem alcançado resultados positivos quando implantada. Com base em um roteiro sugerido em material gráfico de apoio, como folder ou e disponibilantes realizam passeios diferenciados, de acordo com seus interesses realizonibilidades, seguindo as indicações e informações. Os roteiros podem ser realizados a pé ou através de ônibus, metrô, carro ou táxi, dependendo da distância entre os diferentes atrativos sugeridos. Os roteiros a pé são os mais indicados, por e, no ca visitante em contato direto com o atrativo e com a "atmosfera" do loca "pedestrianizadas". 
Outra alternativa interessante para o Centro é o incentivo à sitação de atrativos através do metrô. Neste caso, muitas estações podem scr também computadas como atrativos e como locais ideais para a realização de pequenos eventos artístico-culturais. Para isto a criação de um guia do metrô con indicanos dos atrativos turísticos localizados nas suas imediações é fundamental. O metrốde Washington, EUA, por exemplo, possui um folder destinado à utilização turística que é distribuido gratuitamente nas próprias estações. As linhas de metrô de São Paulo e seus atrativos também já foram divulgados pela mídia impressa, porém sem a realização efetiva de material de apoio.

A abordagem de diferentes temáticas para a sugestão destes passeios, sejam eles auto-guiados ou monitorados por guias especializados, éum elemento que precisa ser mais trabalhado, frente à abrangência de opções para roteiros diferenciados que o Centro oferece. Na cidade de Virginia, EUA, por exemplo, o roteiro Restored Historic Gardens in Virginia é um dos mais procurados pelos visitantes, cxatamente pela singularidade do atrativo destacado. $\mathrm{O}$ mesmo acontece com o rotciro Historic Walkin Tour of Downtown Wilson (Wilson, Carolina do Norte, EUA). Como apenas um exemplo do que pode ser desenvolvido na região central, destaca-sc um roteiro com base nas "andanças" do escritor modernista Mário de Andrade.

Uma linha especial de ônibus, com ponto inicial e final no próprio Centro, que realiza um tipo de city-tour pelos atrativos de maior destaque da região central é também uma boa alternativa para o turismo e lazer. Seu roteiro, frequiência e horários devem ser estudados de acordo com a demanda, tendendo para um maior número de passeios realizados durante o fim de semana. A utilização destes passeios pela rede pública e particular de ensino deve ser incentivado, como elemento complementar à educação formal.

Além das informações constantes nos guias para roteiros auto-guiados ou não, é importante que seja feita uma identificação eficiente de atrativos c logradouros de interesse, através de sua sinalização. Mais que o nome do atrativo, a sinalização (feita em placas que combinem com as características do monumento cm destaque) deve conter outras informações complementares sobre sua história e características peculiares. Para ruas e outros logradouros, sugere-se a citação de seu antigo nome, se existente, com a devida explicação de seu significado. Esta é uma interessante forma de se divulgar a história urbanística do Centro.

Além das alternativas já propostas, a principal utilização do Centro na educação formal será alcançada através da implantação da visitação de edifícios de valor histórico-cultural pela rede pública e particular de ensino. O turismo e o lazer têm profundas ligações como o processo educativo, por constituirem-se em oportunidades de aprimoramento científico e cultural. Os ensinamentos oportunizados durante o contato com os atrativos, por exemplo, complementame revitalizam o aprendizado escolar. É por este motivo que muitas escolas têm se utilizado de passeios e excursões como complementos à sala de aula. Um exemplo atual é o projeto "Vivendo a História de Campinas", cuja proposta básica foi a utilização do turismo como instrumento pedagógico para o ensino da história, através da
1) um passeio no qual se visitavam monumentos, predios e locais onde (...) vivencia, un significativos, ao mesmo tempo em que tentava reviver, através de aconlecem falo sociedade da época correspondente.(Barreto:1992, 41)

en projeto pode ser implantado na rede pública de ensino estadual Este tipo de projetor em fator importantíssimo como auxiliador ao ensino emunicipal, podendoria Municipal de Cultura já conta com trabalhos similares de história. A Secrea Departamento de Serviço Educativo, que realiza, através do projeto São Pauloem Três, visitas pedagógicas ao Centro da cidade. Oprojeto inclui uma fase de treinamitações. Além de pedagogicamente indicado como recurso de estudantes a visitações. Além dinha contato complementar ao ensino, o conhecimento in loco do que antes se tinha contato apenas nos

Complementando as funções sociais que podem ser desenvolvidas através deste projeto, a criação de um serviço de guias mirins pode ser uma alternativa viável para menores abandonados que vivem na região. Este item deve ser desenvolvido a longo prazo, com o auxílio de entidades que trabalhem com menores carentes. É uma forma de afastá-los das ruas, oferecendo-lhes inclusive, remuneração pelos trabalhos prestados. Projeto semelhante foi desenvolvido na região do Pelourinho, onde crianças carentes da própria comunidade do bairro trabalham como guias na região. O treinamento c aprendizado da História e das características do local é facilitado pela intensa vivência que estas crianças têm da área, conhecendo todos os logradouros e monumentos ali instalados, faltando-lhes apenas a aprendizagem de seu siginificado histórico.

Outra alternativa para a formação de uma mão-de-obra especializada é a criação de convênios entre órgãos responsáveis pelo turismo paulistano e cursos superiores de Arquitetura, História c Turismo. A Universidade de São Paulo, por seu caráter público e gratuito, tem o compromisso moral de desenvolver trabalhos que beneficiem a comunidade c poderia ser uma cxcelente fonte de mão-de-obra especializada para as atividades turísticas e de lazer no Centro. Além disso, o envolvimento do corpo discente e docente destes cursos deverá contribuir para a introdução de conceitos e práticas atualizadas c para a própria extensão dos conhecimentos sobre a região, levando, também aí aprim

Esta mão-de-obra deverá ser utilizada não somente para o trabalho de monitoramento, mas principalmente como estagiários envolvidos com a administração e planejamento do turismo, cultura e lazer para o Centro.

No caso de serem utilizados como monitores, em nenhum momento haverá concorrência com os guias mirins. Como serão muito mais especializados, os monitores atenderão a um público que necessita de esclarecimentos e informações especiais, com. Já é comum em muitos países da Europa a organização de roteiros complementa ênfase em determinados assuntos, que servem como possíveis Direito Direito, por exemplo, podem dar realização na cidade. Congressos da área de 
atrativos do Centro, como a Faculdade de Direito da USP c o fónum. Para a organização destes roteiros (que podem contar com cxplanações c palcstras de profissionais da área em questão, além de outros recursos complementares) e posterior acompanhamento dos grupos, é necessário um intenso contato entre as cmpresas organizadoras de eventos c os órgãos responsáveis pclo turismo na cidade, que organizarão tais tours. A Anhembi Turismo e Eventos de São Paulo poderia responsabilizar-se pela viabilização deste projeto. O tema pode cxtender-se a quaisquer outros eventos ocorridos na cidade, como congressos, feiras, encontros, convenções, exposições etc.

Considerando-se o desejo de transformar o Centro num dos pólos culturais mais importantes da cidade, a dinamização e organização freqüente de atividades culturais, artísticas c esportivas na região deve ser intensificada. Apresentações como a da Sinfônica de Boston, do cantor Caetano I'eloso ou do grupo de rock Paralamas do Sucesso no Vale do Anhangabaú, a programação de exposições como A Cidade e seus Fluxos ou a organização de caminhadas ou ginástica voluntária para a população são eventos que devem ser fomentados e intensificados.

A ampliação das atividades do Museu da Cidade deve ser uma das metas de planos referentes à cultura para o Centro. Uma programação mais ampla e melhor divulgação devem ser incentivadas, já que esta é uma das poucas instituições museológicas localizadas na região. Aqui cabe acrescentar que a criação de museus e centros culturais deve ser pausadamente estudada, já que o maior problema dos museus da cidade não se encontra em questões de quantidade, mas na conseqüente fragmentação da memória que o grande número de instituições, muitas vezes mal trabalhadas, acarreta.

A produção de material especial para divulgação deve ser trabalho realizado pela Anhembi Turismo e Eventos de São Paulo e Secretaria de Esportes c Turismo do Estado. Se as verbas para este destino são escassas, uma parceria entre estes órgãos e empresas privadas do setor turístico, assim como entidades representativas do trade, seria indicada. O importante é que se produza material de excelente qualidade, atualizado e moderno e que os trabalhos de divulgação não sejam exaustivos a materiais impressos (folders, mapas, guias etc.), mas possam contar com o auxílio de toda a mídia, escrita ou não.

É importante também ques estes órgãos invistam em levantamento de dados sobre o turismo receptivo paulista, através de um necessário aprimoramento de seus planejadores e técnicos responsávcis por este item. A ausência de dados estatísticos completos e confiáveis, apesar de não ser um privilégio paulistano, é fator que dificulta trabalhos de planejamento do turismo na cidade e sua má qualidade pode afetar os projetos a serem desenvolvidos, acarretada pela utilização de premissas distorcidas ou mesmo completamente falsas. A responsabilidade por cstes dados deve ser arcada pela Anhembi Turismo e Eventos de São Paulo e pela Secretaria de Esporte e Turismo do Estado, por serem os responsáveis oficiais pelo turismo na cidade, e não por entidades representativas de setores do trade turístico.

A atualização dos quadros de funcionários destes órgãos, sejam planejadores ou técnicos, é fundamental, pois a defasagem teórica e a carênca de informações são ristemente presentes nos representantes oficiais do turismo paulista. caracteristicas tristemen político e a conseqüente absorção de uma A quebra de um ciclo de apa só traria aspectos positivos para a atividade.

ma-de-obra especializada so turismo e do lazer como Se opção definitiva pelo desenvolvimento do turismo e do lazer como atividades geradoras de desenveśrios e responsáveis pelo setor não mais encarem tomada é necessário que os empridade constituída por hotéis e eventos. É preciso o turismo apenas como uma atividade constituida por hotiva de maneira ótima investir ou criar suportes para que a atividade se desenvolva de maneira otima,

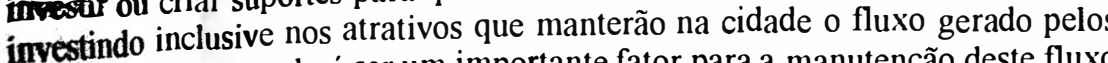
investindo intro poderá ser um importante fator para a manutenção deste fluxo centos. OCentro podiva e eficiente. Para tanto, a mais na cidade, se trabalhado de maneira mais efetiva e eficiente. Para tanto, a mais na cidade, se diretrizes aqui traçadas será a implementação de um programa de importanticaçãodos valores da região, tendo como público-alvo toda a população pautistana, $p$

turismo na cidade.

warisno nxiste uma enorme gama de ações que poderão contribuir para a realização ( deste trabalho. A mide processo, como já ocorreu anteriormente na campanha Patrimônio, realizada pela Fundação Marinho/Rede Globo de Televisão ou no concurso Olhe e Descubra o Centro de São Paulo, organizado pelo Museu Banespa epelo jornal "O Banespiano", ligados ao Banco Banespa, cuja sede está localizada na região central.

Ainda como fator auxiliador, uma ampla distribuição do mapa da região, elaborada pela Associação Viva o Centro, deveria ser considerada, contando com o patrocínio das várias empresas envolvidas por tal associação. A adequação deste mapa em formato de bolso é interessante. A elaboração e produção de folhetos imformativos sobre a história da cidade e de edificações emblemáticas poderia se também viabilizada, assim como a edição de livros e guias, através do caminho do patrocínio.

Outro dispositivo a ser utilizado para a conscientização seria a reorganizaa do Museu de Rua, ligado ao Departamento de Patrimônio da Secretaria Municipal de Cultura. Em determinados pontos de intenso tráfego de pedestres, painéis fotográficos de aproximadamente $1,80 \mathrm{~m}$ de altura mostrariam imagens do próprio logradouro onde estão expostos, com pequenos textos explicativos. Exposiçes já realizadas sobre o viaduto do Chá, largo da Memória, vale do Anhangabaú e praça da Sé foram grandes "sucessos de público" e desestigmatizaram a imagem epopulação frente aos museus, adotando características dinâmicas de abordagem iuseográfica. A exposição realizada no topo do edificio Martinelli segue a mesma

Até aqui falou-se que um incremento das atividades de turismo e lazer no
a cen passa por uma revisão, ampliação e atualização das propostas dos órgãos participacis por estas atividades na capital. Mas tão importante quanto isto será a sejam da ár da iniciativa privada. A captação e atração de empresas particulares, sejam da área turistica, de lazer e de serviços de apoio a estas duas atividades deve 
ser intensificada. Em fins do século XIX o Centro da cidade fervilhava de restaurantes, bares, lanchonetes, cafés, livrarias, cinemas e teatros $\mathrm{c}$ cram estes or responsáveis pelas características vitais da região. A atração destes prestadores de serviços pode trazer de volta esta diferença, inclusive pelas distinções de pólo de lazer, cultura e turismo que se deseja para a área.

\section{Consideraçōes Finais}

A revitalização, amparada somente numa recuperação de fachadas que maquiará o Centro, já se provou ineficaz para situações referentes à atividade turística e em nada reverterá o processo de abandono, se outras iniciativas fundamentais não forem efetivadas. Da forma que vem sendo tratada, a revitalização será apenas um processo de embelezamento de alguns edifícios, que contribuirá somente para alguma valorização pecuniária e em nada para a qualidade de vida dos usuários do Centro e dos cidadãos da Metrópole, que de alguma forma arcarão com os gastos do processo, sem a utilização de seus benefícios.

Para que o Centro não se transforme em um atrativo "inanimado", seu uso para o turismo e para o lazer deve se basear na interpretação, uma das mais modernas técnicas de aproveitamento de atrativos turísticos, neste caso históricos. Os recursos oferecidos por esta técnica contribuirão não apenas para um melhor aproveitamento do Centro como fator de entretenimento, mas também para a educação da população, para a criação de uma maior consciência de sua importância histórica e cultural e a conseqënte necessidade de sua preservação.

Os atrativos históricos e arquitetônicos, localizados principalmente no Centro Velho, amaprados por um planejamento para o turismo e lazer, pelo desenvolvimento de uma infra-estrutura de apoio de boa qualidade, pela efetivação de programa voltado para sua recuperação e pelas técnicas de interpretação histórica transformarão a região num importante atrativo complementar ao turismo de negócios. Sua utilização se dará, também e principalmente, pela excelência das características voltadas ao lazer urbano do paulistano. A utilização racional da região dependerá de esforço conjunto de todo o setor turístico e cultural, além de grande vontade política dos órgãos administrativos paulistas.

A revitalização do Centro e sua utilização como fonte de lazer para população e como atrativo complementar à atividade turística se provará importante por reverter-se positivamente não só para aqueles que de alguma forma se beneficiariam diretamente pela revitalização, por possuírem imóveis ou negócios no Centro, mas para toda a população por constituir-se em fator de resgate da identidade original do paulistano:
BIBLIOGRAFIA

ssociação VIVA O CENTRO. 1993. Viva o Centro. Documento 4, set.

ASSOCIACAO Urismo em na ise, o au o, v. , n. ,

p. 3444, nov.
COOPER, Chris, 1981. The technique of interpretation. In: BURKART, A. S. MEDLIK, S. Managing COOPER, Chris, 1981. The techiqu \& Heinemann, p. 224-30.

tourism. Londres: Butterworth \& Marketing em localidades historicas e turismo cultutal. Turismo em PIRES, M. J. \& BAS

Análise, São Paulo, V. 4. 1978. Culture as determinantof the attractiveness of a tourism region. Annals RITCHIE, J.R. B. \&ZINS, Wisconsin, v. 5, n.2, p. 252-67, abr.jun.

of Tourism Research, Wisconsin, SÃO PAULO (Municipió. Såo $\mathrm{P}$

(0).
COSTA, F R. 1994. O processo de recuperação do Centro de São Paulo e sua importância para o turismo na capita pa

20 heritage tourism. In: BURKART, A. J. MEDLIK, S Managing tourism. Londres: Butterwoth \& Heinemann, p. 115-21. 